\title{
'THERE'S No APHRODISIAC LIKE NewTown': The Evolving Connection To Place In The Music of The Whitlams
}

\section{Transforming Cultures eJournal, \\ Vol. 4 No 1 April 2009 http://epress.lib.uts.edu.au/journals/TfC}

\section{Liz Giuffre ${ }^{1}$}

\begin{abstract}
The Whitlams live in Newtown, Australia" is a byline that has appeared on each of the Sydney band's albums since their beginnings in 1992. During this time the band has progressed from being on a small, independent label with a local audience to achieving national coverage and recognition, culminating with 8 ARIA award nominations in 1998. Of these they won three for Best Group, Song of the Year and Best Independent Release. Following this The Whitlams were signed to Warner Music (as it incorporated Festival Music), and have continued to make albums that still use inner city Sydney as a focus, but are pitched at a less localised audience. The Whitlams have used Sydney as a setting for major local events during this time, (the Sydney Olympics, State Government policies), but also just as a setting to express more personal issues (songs about relationships, aging). This paper will compare The Whitlams' early releases to the music made after the band gained national attention, looking at how and why Sydney has remained a central theme, but has been expressed in different terms.
\end{abstract}

\section{Introduction}

Since their beginnings rock group The Whitlams have been strongly associated with a sense of place. Formed in the inner west Sydney city suburb of Newtown in 1992, the band has been connected with that suburb throughout their career, a connection maintained by songwriter Tim Freedman and utilised in the marketing of live performances and recorded work. Carroll and Connell (2000) have already provided a valuable examination of The Whitlams' early work, and this article uses their conclusions as a foundation for further analysis of the band's more recent music. Since

\footnotetext{
${ }^{1}$ Liz Giuffre teaches at Macquarie University.
} 
2000 The Whitlams have continued to release music that evokes a sense of place, however these evocations are created using significantly different methods to those employed by the band in their earlier work. This paper argues that it was not until the band was removed from Newtown (by virtue of touring more expansively and signing to a major record label) that they began to feel the need to depict a sense of place in their lyrics.

Connections between music and place have been made by scholars of all types of music. While Stratton and others have acknowledged "the problems of place [and the assumption that there can be a] relationship between a particular sound and/or lyric and a certain geographical location" (Stratton, 2007: 377), there remains much to be gained by continuing to explore such connections. In the seminal Australian popular music text From Pop To Punk To Postmodernism (1992), Turner argued that scholarship that connects music and place is most useful when focused on the context of musical creation, and that "focusing on such contexts helps us understand what pleasures are produced for consumers, and highlights the multiplicity of experiences produced by music" (Turner, 1992: 13). Using Turner's suggestion and heeding Stratton's warning, this article will observe the way references to place have changed over The Whitlams' career and will articulate the context of such changes. I will show how Freedman as a songwriter has utilised place to provide a sense of continuity and familiarity, and particularly how he has increased the frequency of lyrical references to place in response to the changes in the way his music has been consumed.

\section{Ways of reading music and place}

Connell and Gibson (2003) suggest that musicians create connections between music and place in order to attract and maintain audiences. While they acknowledge that "notions of 'local sounds' are always fluid and not always successful" (99), the authors assert that distinct musical evocations of place allow for a connection between audiences and musicians. Building on well-established formulations of community and nationalism such as Anderson's “imagined community” (1983), Smith's notion of an “imagined musical community" (2005: 193- 202) ${ }^{2}$, and Cohen's examination of musical

\footnotetext{
${ }^{2}$ Smith uses this term to refer to how Australian country music functions particularly, as well as "in the middle" musicians such as Paul Kelly (2005: 186-7).
} 
“scenes" (1999), Connell and Gibson argue,

the archetypical pop song creates an 'imaginary identification' between the consumer and performer, where the perceived value of the song - its emotional conversation-becomes its exchange of values and the key to success (2003: 71).

Connell and Gibson concede that imaginary identifications between audiences and musicians appear in many types of popular music, however they suggest that these associations "may be enhanced by [lyrical] links to place" (2003: 71), a view of lyrics consistent with Frith's (1988) benchmark study of the function of lyrics in popular music ${ }^{3}$. As Frith describes lyrics serve to create "direct relationships" (1988: 124) in popular music, relationships that help audiences attribute particular meanings to popular music texts. Although Connell and Gibson acknowledge that songwriters occasionally use lyrics to be deliberately subversive with listeners ${ }^{4}$, overwhelmingly they subscribe to a view similar to Frith's. Following this lead, I will now examine the presence of Newtown in The Whitlams' lyrics. When asked early in his songwriting career about The Whitlams' music, Freedman answered definitively, "I think the only thing we've got going for us is our lyrics. There are plenty of [bands that use] pianos around" (Freedman in Grimson, 1998:36). More recently, Freedman offered a similar view of the importance of lyrics in The Whitlams' music with his commentary on song lyrics released on the band's website in conjunction with the album Little Cloud (2006) ${ }^{5}$, as well as part of the packaging of the CD release of the band's 'Best Of' compilation, Truth, Beauty and a Picture of You (2008). Freedman's acknowledgement of the importance of lyrics to The Whitlams' appeal has also motivated my choice to use lyrics as the focus of this study.

\footnotetext{
${ }^{3}$ Frith continues to argue in this chapter about the importance of acknowledging the "words" in songs in their musical context, stating, "Songs aren't just any old speech act - by putting words to music, songwriters give them a new resonance and power" (1988: 124)

${ }^{4}$ Connell and Gibson cite the example of John Lennon as a songwriter who deliberately tried to sabotage audiences who tried to interpret his lyrics. As the story goes, after completing the lyrics to "I Am The Walrus", Lennon famously commented, "let the fuckers try and work that one out" (Lennon in Connell and Gibson, 2002: 71),

${ }^{5}$ This replicated the press material released at the time. See www.thewhitlams.com, accessed 5/5/08
} 


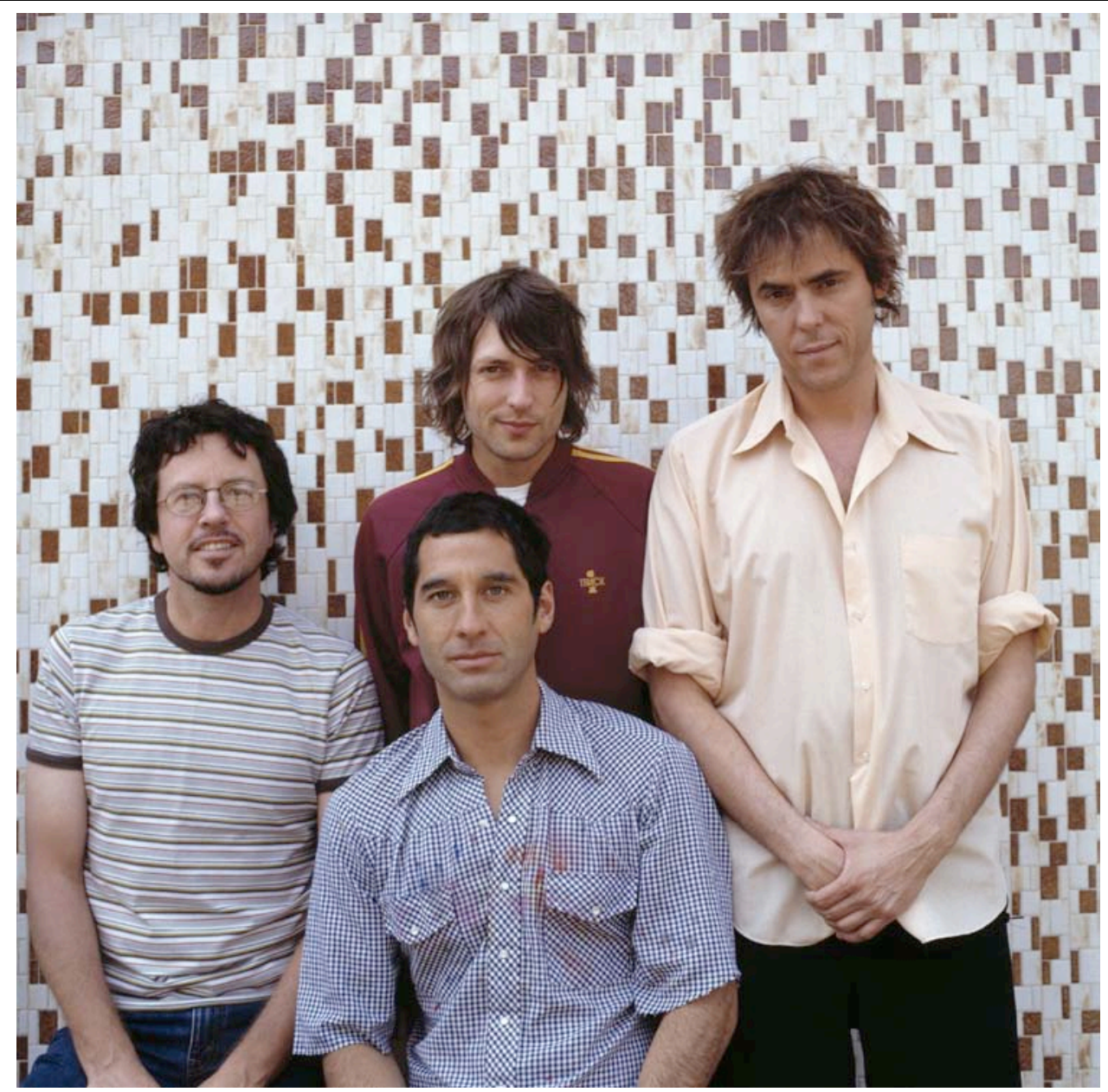

The Whitlams circa 2008. Photo supplied by Warner Music.

\section{Looking for Newtown in The Whitlams' lyrics}

There is a popular perception that The Whitlams' overuse references to Newtown in their lyrics. This perception was used as the basis of a parody of the band on the Australian television comedy program The Chaser's War on Everything (2007). Impersonating Freedman and borrowing melodies from Whitlams' songs, comedian Andrew Hansen presented "The Newtown Song" (aired on ABC TV, 3/10/07), a song that had entire verses composed solely of names of Newtown pubs and other local attractions. Culminating with the line "there's no aphrodisiac like Newtown" (a play on The Whitlams' celebrated single "No Aphrodisiac"), Hansen jokingly accused the band of excessive repetition, and claimed that Freedman had written "1000 songs and they're all about Newtown". Impersonating Freedman, Hansen concluded the parody by walking away from the piano mid-song, saying that he couldn't finish because he'd "run out of Newtown references".

Freedman responded to the parody shortly after it was aired. As part of a lighthearted 
rebuttal, he wrote:

I have only mentioned Newtown once in over 80 songs, on our sixth album last year. Before that you have to go back 8 years where I named 2 local pubs in a song about the pokies. And the first 3 albums? Not a single reference. More pointed perhaps would have been the question as to why I so willingly bathed in the cachet of fine old Newtown when I had written so very little about it, and had only lived there for 20 years (not quite enough to be deemed a "local" around these parts). (Freedman as quoted in Cashmere, 2007, $<$ http://undercover.com.au>, accessed 4/4/08)

While not deliberately antagonistic in either purpose or expression, Freedman's response demonstrates a gap between the public perception of his music and its actual lyrical content. In this section I will test Freedman's assertions by conducting a lyrical analysis of the band's use of place over their career, examining how associations between The Whitlams' music and place have been established, and what the consequences of these associations have been.

Upon reviewing the lyrics in six of The Whitlams studio albums to date, I found no overt lyrical references to place until the band's third album, Eternal Nightcap (1997) (see appendix). This is not to say that the band weren't connected to Newtown at all during this time, but that these connections were made as part of discourse outside the band's music ${ }^{6}$. For example, in one of the first feature articles written about The Whitlams in the Sydney Morning Herald, journalist Peter Holmes (1994) used place and the band's name to introduce the new musicians to the newspaper's audience. Holmes called the article "Men and Women of Newtown", a choice which gave Newtown and the band's namesake equal footing ${ }^{7}$. While harnessing a band's name and its geographical origins is a reasonably common journalistic tool ${ }^{8}$, Holmes' article helped to establish a distinct pattern for the way The Whitlams would come to be considered by the media and audiences ${ }^{9}$. As Connell and Carroll (2000) confirmed, such reports

\footnotetext{
${ }^{6}$ The band did write a couple of songs about Newtown and other places prior to 1997, however these weren't included on any of their albums.

${ }^{7}$ This heading draws on a famous election speech Gough Whitlam gave in 1972 which began "Men and Women of Australia".

${ }^{8}$ For more detail on rock criticism see Mark Fenster's discussion of the role of the music critic in terms of answering questions about an artist for the potential audience (2002: 85-87). Connell and Gibson also discuss place as a generally accepted interview topic, "this sense of finding geographical roots for musical sounds and styles, of locating the artist or the scene in physical space, is a dominant theme in the music press, artist biographies and rockumentaries." (2003: 91)

${ }^{9}$ This was a pattern that would be repeated in local free-to-street and specialist music press as well. See for example Clelland (1999) in the Sydney street press Drum Media, and Grimson (1998) in Australian
} 
"reinforced the link to Newtown" (145) when The Whitlams were presented to audiences.

The band also created their own link to Newtown by ending the liner notes of their first four albums with the declaration, "The Whitlams live in Newtown, Australia." Using this declaration as a coda to each album, The Whitlams invited audiences to identify the experience of listening to their music with the experience of living in and visiting Newtown. Also, by articulating "Newtown, Australia", rather than "Sydney, Australia", or "Newtown, Sydney", The Whitlams directly appealed to audiences with specific local knowledge of the area. This directed audience address was demonstrated as the band amended the declaration on their live album Stupor Ego (1996) to read: "The Whitlams can't afford to live in Newtown, Australia". As Homan (1999) noted in an examination of changes in Newtown at the time, The Whitlams' comments via these liner notes were particularly indicative of community morale in the area of the time, and in his opinion could be considered the "best reflect[ion]" (1999: 61) of the consequences of urban gentrification on artists in that setting at the time ${ }^{10}$. The Whitlams' acknowledgement of the impact such changes were having on their music making aligned their experiences with those of their core audience.

Eternal Nightcap (1997) was the first of The Whitlams' albums to feature specific lyrical references to place. The band's third formal studio album and first to be a nationally recognised commercial success ${ }^{11}$, Eternal Nightcap features four songs containing lyrical references to place: 'You Sound Like Louis Burdett'; 'Melbourne'; 'Charlie \#1' and 'Up Against The Wall'. The two latter songs feature only fleeting references to place (see appendix), however in 'Louis Burdett' and 'Melbourne', two of the singles from the album, place is used as part of each song's lyrical content and its overall function. Written and recorded while the band was still on independent label Black Yak/Phantom Records, 'You Sound Like Louis Burdett' uses place as an exercise

\section{Rolling Stone.}

${ }^{10}$ See also Homan's later work on this topic with Gibson (2004). Gibson and Homan argued that during the 1990s particularly the types of practices that had made the Newtown appealing in the first place were being driven out, "creative producers add critical cultural currency to these places ... yet those creative workers ... are effectively moved on through rising rents" (2004: 70).

${ }^{11}$ According to music journalist Bernard Zuel, The Whitlams' career as a result of Eternal Nightcap was highly unusual; "No Aphrodisiac' sold more than 80,000 copies on its own and sent sales of the Whitlams' third album, Eternal Nightcap, past 200,000 - the sort of figures rarely reached by local acts and never by independent artists" (Zuel, 2002: 1) 
in inclusiveness by creating jokes that rely on knowledge of Sydney's Eastern and Inner Western Suburbs. For example, in this song's lyrics Freedman assumes that an audience would recognise the lyrics "it never rains in Tempe" as a reference to the suburb's ambiance under a major flight path, and "the time [it takes to] get to Marrickville" as indicative of only a short distance. Further to these, Carroll and Connell (2000) argue that with 'You Sound Like Louis Burdett' the band established Sydney as "a place of enclaves and social divisions" (2000: 148), a relationship that ultimately "perpetuat[ed] stereotypes and further[ed] Sydney's perceived social fragmentation" (147). Carroll and Connell suggest that audiences would still recognise the comfortable home base central to the song's action as being Newtown even though this is not expressly stated.

However, as I discovered in a previous study of The Whitlams' music (Giuffre, 2002) ${ }^{12}$, with Eternal Nightcap The Whitlams began to attract wider interest, particularly from audience members from outside Sydney. These listeners without an intimate knowledge of the city may not have noticed Newtown's implied 'presence' in songs such as 'Louis Burdett', and as such may have had difficultly relating to them in the same way local audiences did. For example, as an Adelaide based listener commented, "I don't recognise places like Tempe, Marrickville ... they're more Sydney-isms, that I recognise as Tim [Freedman]-isms." (FOW Emily, as quoted in Giuffre, 2002). This sentiment was echoed by a Canadian fan MK, who was also not very familiar with Sydney. In the absence of being able to relate to place through a shared experience, MK responded to another aspect of The Whitlams' music, projecting a common experience of bilingualism by referencing to Freedman's use of French lyrics alongside English in "Love is Everywhere" ${ }^{13}$, saying "When I listen to 'Love Is Everywhere' I feel like [Freedman] has had the same experience of two languages I have had. He seems to be part Canadian" (MK quoted in Giuffre, 2002). As this small audience sample shows, listeners in different parts of Australia and the world did not respond to lyrics that only hinted at Newtown in the same way that local audiences did. As The Whitlams' began to attract the attention of audiences other than those based in the local area, this

\footnotetext{
${ }^{12}$ My previous study relied on an ethnographic study of The Friends of the Whitlams (FOWs) fanclub, conducted during 2001 as part of an honours thesis and later presented at the IASPM Australia New Zealand branch conference in Armidale, 2002. The study was based on fan responses to a short questionnaire posted to the fanclub weblist during 2001. There were 31 respondents from all over Australia as well as Canada and the UK. All responses are credited to the respondent's online pseudonym, and were reproduced with their permission. I refer to them in this paper only by pseudonym and the date their response was emailed to me.

13 'Love Is Everywhere' features on Eternal Nightcap.
} 
disparity began to have greater consequences.

\section{Mainstream success}

Lyrical references to place became more prominent after The Whitlams signed to major record label Warner. Following the success of Eternal Nightcap, The Whitlams negotiated a deal with the record label that allowed the band to maintain a significant level of control of over their working practices while also benefiting from the resources of the major label's industry infrastructure ${ }^{14}$. As one journalist described, this deal was central to the band achieving a new level of success, to "break[ing The Whitlams] out of the Newtown ghetto" (Zuel, 2002: 4). Freedman expressed a desire to move away from his association with Newtown just prior to the release of the band's first album with Warner, Love This City (2000). When asked if Newtown was "a type of muse" for him, Freedman indicated he wanted to change the songwriting pattern he'd earlier established,

No, [Newtown is not a muse]. I don't think Newtown is the most romantic setting for a song - it is just that I happen to be here ... [the band] don't inhabit Newtown like we used to... it is becoming a little untrue to say Newtown affects our every pore (Freedman in Bowen, 2000: 9).

This comment demonstrates Freedman's understanding of the relationship between The Whitlams' music and place early in their career, and importantly, it also highlights his desire to change this relationship. These changes can be observed in the recordings released after this time.

As indicated by its title, Love This City featured songs connected more overtly to place than any of The Whitlams' previous albums. The title track (initially released in 1995 as the "Sydney Olympic Theme"15), was written about the announcement of the Sydney Olympics, however by the time it was re-released as 'Love This City' in 1999 specific references to Sydney were removed ${ }^{16}$. Except for a reference to "Taylor Square" and

\footnotetext{
14 The negotiations surrounding The Whitlams deal with Warner music was reported in Mathieson (2000: 239-40), and in an interview with the Sydney Morning Herald in 2002 Freedman described the band's relation, "We have our own label, we license The Whitlams to Warners" (Freedman in Zuel, 2002: 1).

15 "Sydney Olympic Theme" appeared as a b-side to the "I Make Hamburgers" single (1995). Although re-recorded and with a slightly different structure when renamed and released as "Love This City" (1999), it is easily recognisable as the same song with the same lyrics and melody.

${ }^{16}$ As I found in my previous study, Sydney-based fans were particularly fond of the song and could identify with its perspective. For example, as FOW Rochelle explained, The Whitlams' references to
} 
"the foreshore", the song could have been understood as a narrative about any city's preparations to host a major international event. Therefore, unlike earlier songs like 'Louis Burdett' that relied on an audience's detailed knowledge of a small geographical area, the 1999 version of 'Love This City' positioned place more generally, allowing audiences from a range of different places to engage with the song's lyrical narrative. This more general use of place is also evident in the album's other main single, 'Blow Up the Pokies'. Along with 'God Drinks at The Sando', 'Blow Up The Pokies' is one of two songs on Love This City written about Newtown pub culture, specifically The Sandringham and The Shakespeare Hotels. Although both of these pubs would be recognisable to audiences familiar with Newtown and its surrounds, a specific location is not central to the song's narrative as it was in earlier Whitlams' work like 'Louis Burdett'. The central theme of 'Blow Up The Pokies', an exploration of the consequences of gambling addictions, does not rely on Newtown as a specific setting for the song's action, but instead could be set in any number of cities with high gambling rates.

This move away from specific to general uses of place coincided with significant commercial success for the band. 'Blow Up The Pokies' was The Whitlams' most successful commercial single upon release, appearing on 70 radio stations across Australia (Freedman in Clelland, 1999: 37). Since then the song has become a more recognisable anthem for the band than their career-changing single 'No Aphrodisiac', and features prominently as the second track for The Whitlams' Best of compilation, Truth, Beauty and a Picture of You (2008). With these singles and the album Love This City, distinct changes in The Whitlams' use of place can be observed. By using less specific lyrical markers of place than in their earlier works, The Whitlams changed their method of audience address.

\section{A move away from Newtown and a perceived loss of authenticity}

With Little Cloud (2005) Freedman again increased the incidence of lyrical references to place, and to Newtown particularly. Again, this increase coincided with a period of writing away from home, specifically Freedman's physical and emotional escape from

\footnotetext{
Sydney in song lyrics allowed her to create a sense of identity through shared experience, "In 'Love This City', he [Freedman] captures how Sydneysiders felt about winning the Olympic Games, we were over the Games before they had begun" (Rochelle 27/7/01, as quoted in Giuffre, 2002).
} 
Newtown to New York for a few months (Zuel, 2006: 5-6). This period also followed the relatively disappointing reception of the band's 2002 album Torch The Moon ${ }^{17}$. On Little Cloud lyrics describing place were used to invite an exchange with the audience, in this instance an exchange based on feelings of homesickness and displacement rather than a celebration of belonging. Freedman references Newtown directly in two songs, 'Year of the Rat' ("Taxi from the airport to the Paris end of King”) and '12 Hours' ("King St"), and engages with the area indirectly in at least one other ${ }^{18}$. As one reviewer suggested, Little Cloud relied on lyrical references to place to create an overarching theme for the album, with the development of a narrative of "New York juxtaposed with Newtown" (Zuel, 2006: 5) providing coherency for the album as a whole.

Freedman's decision to directly include Newtown in The Whitlams' lyrics at this stage in the band's career reasserts a sense of authenticity between music and place that may have been jeopardised by the band's commercial success ${ }^{19}$. Stratton noted a similar pattern with the career of Western Australian band The Triffids (2007), particularly noting after their success that "all the band's recordings were made outside Western Australia while often referencing Western Australian images" (Stratton, 2007: 396). Stratton concluded that making music about a place while working somewhere else led to a sense of "painful nostalgia" (2007: 397) driving The Triffid's music, a pain built on homesickness. For Freedman and the later work of The Whitlams, Newtown's presence is also most obvious in music written while he was living elsewhere.

Connell and Gibson's (2003) argument about place as a marker of authenticity in music is particularly relevant to The Whitlams' career as it has evolved over time. Although defining the authentic is problematic in itself ${ }^{20}$, a sense of authenticity is often cited as an important factor in discussions of music and place ${ }^{21}$, with authenticity assigned

\footnotetext{
${ }^{17}$ Compared with Love This City, Torch the Moon was a relative disappointment for The Whitlams in terms of radio airplay, with the album failing to contain a single with the same mainstream appeal as "Blow Up the Pokies".

${ }^{18}$ In 'I Was Alive' references to the relationship between Newtown and Sydney's undesirable "Eastern Suburbs" are also present, with descriptions of the East as relatively uncomfortable and superficial; similar to the relationship articulated in the lyrics of 'Louis Burdett'.

${ }^{19}$ Further to Connell and Gibson's discussion of the loss of perceived authenticity through commercial success, see also Hesmondalgh's discussion of authenticity and independent musicians (1999).

${ }^{20}$ See particularly Moore (2004).

${ }^{21}$ For example, there are a number of articles that deal with music and place in terms of authenticity in Bennett and Peterson's edited collection Music Scenes: Local, Translocal and Virtual (2004). See particularly Urquia's discussion of the connection between perceptions of authenticity and London based
} 
ultimately through evidence of a shared experience. Referencing Carroll and Connell's examination of The Whitlams' early work, Connell and Gibson surveyed relations between music and place in the work of a number of Australian bands, concluding,

Performers whose success was national, such as Midnight Oil (who raised issues concerning Australian national consciousness) or primarily local, such as The Whitlams (who sang of gentrification in inner-city Sydney, and demanded audience participation) had little difficulty in being attributed integrity and authenticity, in the face of commodification, commercialism and mass consumerism (2003: 43).

Commercialism and mass consumerism were not significant threats to The Whitlams' musical integrity early in their career, as their locally (and independently) produced recordings ensured that the band could have relatively close contact with their small target audiences. The band and its audience shared the same physical experience of place by living in Newtown side by side, and as such, early Whitlams' albums did not need to use lyrical references to place to assert a sense of the authentic. However, as the band began to tour and move away, and its target audience began to be drawn from a wider geographical area, lyrical references to place increased as a means to maintain a sense of authenticity and ultimately as a means to maintain audience interest ${ }^{22}$.

\section{Conclusions: you can take the band out of Newtown...}

Tim Freedman was right to protest against The Chaser's parody of him and his music, as upon closer examination Newtown does not feature in lyrics of the majority of The Whitlams' repertoire. However, as the band has gained commercial success, Newtown has appeared more prominently in their lyrics. To answer Freedman's question as to why he has "willingly bathed [in] the cachet" of Newtown in his songwriting, this paper has argued that by including lyrics about Newtown in their later work, The Whitlams have attempted to maintain a sense of authenticity that an association with place can deliver. There was little need to assert a connection to place in the band's early work because the band's authenticity was not questioned as they and their audience were

Salsa music, and Grazian's discussion of authenticity and it relates to the way Chicago based blues music is received.

${ }^{22}$ Faris (2004) observed a similar relationship between music, authenticity and place with reference to the independent musicians that formed the core music associated with Chicago in the 1990s, "Like all underground rock styles, the Chicago sound projects a sense of what it means to be an 'authentic' performer" (2004: 433). 
almost exclusively based in Newtown. owever as the band moved away and its audience began to become more diverse, a connection to place (and the sense of the authentic associated with it) was not as apparent. It was not until The Whitlams left Newtown that Newtown began to appear directly in their lyrics.

\section{Bibliography}

Anderson, B. (1983) Imagined Communities-reflections of the origin and spread of Nationalism, Verso, London.

Bennett, A. \& Peterson R.A. (eds) (2004) Music Scenes: Local, Translocal and Virtual, Vanderbilt University Press, UK.

Bowen, N. (2000) "Maintaining the Rage", The City Hub, 10/08/00, p9.

Carroll, J. \& Connell, J.(2000) “'You Gotta Love This City': The Whitlams and Inner Sydney", Australian Geographer, (3)n, 141-54.

Cashmere, P. (2007) “Tim Freedman Laughs Off The Chaser", Undercover Music, published 8/10/07, accessed via <www.undercovermusic.com.au>, 4/4/08.

Clelland, R. (1999) "Freed of Constraints?" in Drum Media, 26/10/99, 23.

Clelland, R. (2001) 'There is such a thing as a Free(dman) lunch)', Drum Media, $8 / 5 / 01,37$.

Cohen, S. (1999) 'Scenes' in Horner, B and Swiss, T (eds) Key Terms in Popular Music and Culture, Blackwell Publishers, Massachusetts, 239-250.

Connell, J. and Gibson, C. (2003) Sound Tracks: Popular Music, Identity and Place, Routledge.

Faris, M. (2004) "“That Chicago Sound': Playing with (Local) Identity in Underground Rock", Popular Music and Society, (27) 4, 429-454

Fenster, M. (2002) 'Consumers' guides: the political economy of the music press and the democracy of critical discourse" in Jones S (ed) Pop Music and The Press, Temple University Press, New York, 81-92.

Freedman, T. (2006) Interview with author conducted by phone as part of media interviews, February 2006.

Frith, S. (1988) "Why Do Songs Have Words?" in Music For Pleasure: Essays in the Sociology of Pop, Polity Press, Oxford, 105-128.

Gibson, C. \& Homan, S. (2004) "Urban Redevelopment, Live Music and Public Space", in International Journal of Cultural Policy, (10) 1, 67-84.

Giuffre, L. (2002) “'With a gun totin' trigger happy tranny named kinky renee': Identity, Australianness and contemporary Popular music", paper presented at $9^{\text {th }}$ Australia/New Zealand International Association for the Study of Popular Music (IASPM) Conference, 19-21 July, University of New England, Armidale.

Grimson, T. (1998) “Tim Freedman” in Rolling Stone: Rock and Roll Yearbook, 36.

Guinness, D. (2006) "41 and counting" in Sunday Life: The Sun-Herald Magazine, 19/3/06, 14-17. 
Holmes, P. (1994) "Men and Women of Newtown", The Sydney Morning Herald, 4/3/94, 7.

Homan, S. (1999) "Displaced rhythms: Evicting Rock and Roll" in Bloustein G (ed) Musical Visions, selected proceedings from the 6th National Australia/New Zealand IASPM and the Inaugural Arnhem Land Performance Conference Wakefield: Kent Town, South Australia, 57-62.

Mathieson, C. (2000) The Sell-in: How the music business seduced alternative rock, Allen and Unwin, Sydney.

Moore, A. (2004) "Authenticity as Authentication" in Popular Music, (21):2, 209-23.

Smith, G. (2005) Singing Australian: A History of Folk and Country Music, Pluto Press, Melbourne.

Steggels, S. (1992) "Nothing ventured, nothing gained: Midnight Oil and the politics of rock" in Hayward P (ed) From Pop To Punk To Postmodernism: Popular music and Australian Culture from the 1960s to the 1990s, Allen and Unwin, Sydney, 139- 148.

Stratton, J. (2007) "The Triffids: The Sense of Place", Popular Music and Society, (30):3, 377-99.

Turner,G. (1992) "Australian Popular Music and its Contexts" in Hayward P (ed), From Pop to Punk to Postmodernism: Popular music and Australian culture from the 1960s to the 1990s, Allen and Unwin, Sydney, 11-24.

Zuel, B. (2002) "No holds bard" in The Sydney Morning Herald Weekend Edition (Metropolitan supplement), 1, 4.

Zuel, B. (2006) 'The Hot Seat: Tim Freedman Talks to Bernard Zuel' in The Sydney Morning Herald Weekend Edition (Spectrum supplement), 4-5.

\section{Discography}

Introducing The Whitlams, Black Yak/ Phantom Records, 1993.

Undeniably The Whitlams, Black Yak/ Phantom Records, 1994.

I Make Hamburgers (single), Black Yak/ Phantom Records, 1995.

Stupor Ego, Black Yak/ Phantom Records, 1996.

Eternal Nightcap, Black Yak/ Phantom Records, 1997.

Love This City, Black Yak/ Warner, 1999.

Torch The Moon, Black Yak/ Warner, 2002.

Little Cloud, Black Yak/ Warner, 2006.

Truth, Beauty and a Picture of You (The Best of The Whitlams), Black Yak/ Warner, 2008 . 


\section{Website Links}

$<$ www.thewhitlams.com $>$

$<$ www.ariaawards.com.au $>$

$<$ www.undercovermusic.com.au $>$

$<$ www.abc.net.au/tv/chaser/war $>$

$<$ http://www.youtube.com/watch?v=bAQu3-Pd7mA->

(Chaser "one more newtown reference"- aired 3/10/07)

\section{Appendix}

\begin{tabular}{|c|c|}
\hline Album & Number references to place \\
\hline \multicolumn{2}{|c|}{ Released independently through Phantom/Blak Yak records } \\
\hline $\begin{array}{l}\text { Introducing The } \\
\text { Whitlams (1993) }\end{array}$ & $\begin{array}{l}\text { None (except "walking around the town", but this is difficult to assume } \\
\text { is "Newtown") }\end{array}$ \\
\hline $\begin{array}{l}\text { Undeniably The } \\
\text { Whitlams (1994) }\end{array}$ & None \\
\hline $\begin{array}{l}\text { Eternal Nightcap } \\
\text { (1997) }\end{array}$ & $\begin{array}{l}\text { Lots although specific and general } \\
\text { You Sound Like Louis Burdett ("Marrickville", "Tempe", "a little thing } \\
\text { to do out East") } \\
\text { Melbourne (name never said in lyrics, but only title) } \\
\text { Charlie \#l (the "harbour shrugs") } \\
\text { Up Against the Wall ("she's one in a million so there's } 5 \text { more just in } \\
\text { NSW") }\end{array}$ \\
\hline \multicolumn{2}{|r|}{ BAND SIGNS TO FMR/ WARNER MUSIC } \\
\hline $\begin{array}{l}\text { Love This City } \\
\text { (1999) }\end{array}$ & $\begin{array}{l}\text { Love This City ("Harbour shrugs", "Taylor Square”) } \\
\text { God Drinks at the Sando ("Sando"- Sandringham Hotel) } \\
400 \text { Miles from Darwin ("Darwin") }\end{array}$ \\
\hline $\begin{array}{l}\text { Torch the Moon } \\
\text { (2003) }\end{array}$ & $\begin{array}{l}\text { Duffy's Song ("I don't believe in Bondi, I don't believe in Rugby } \\
\text { League") }\end{array}$ \\
\hline Little Cloud (2006) & $\begin{array}{l}\text { I Was Alive ("Eastern Suburbs") } \\
\text { Year of the Rat ("Taxi from the airport to the Paris end of King", "easy } \\
\text { being a star in Sydney") } \\
12 \text { Hours ("King St") }\end{array}$ \\
\hline
\end{tabular}


Fondness Makes the Heart Grow Absent ("St Patricks in the snow", "Prince St")- New York

Stay with Me (My home is still my home ... I walk around Ludlow into a bar to not get drunk)- New York 